\title{
METHODS FOR COMPARING DIVERSIFICATION STRATEGIES ON THE SWEDISH REAL ESTATE MARKET
}

\author{
Sigrid KATZLER ${ }^{\text {a,* }}$ \\ a Department of Real Estate and Construction Management, KTH Royal Institute of Technology, Brinell- \\ vägen 1, SE-10044 Stockholm, Sweden
}

Received 8 March 2013; accepted 19 February 2015

\begin{abstract}
This paper compares the effectiveness of different property portfolio diversification strategies using five methods; (1) correlation matrices, (2) efficient frontiers, (3) Sharpe ratios, using three different sub methods, (4) coefficients in equations explaining total returns and (5) R-square values in equations explaining total returns. The evaluation methods are applied to both value weighted and equally weighted indices based on Swedish real estate return data. All methods show that, if any, diversifying over property types is a better strategy on the Swedish market than diversifying over regions. No test yields significant support for regional diversification. The support for the property type strategy is stronger when using equally weighted indices.
\end{abstract}

KEYWORDS: Risk reduction; Property type; Region; Efficient frontiers; Correlation

\section{INTRODUCTION}

This paper is an attempt to investigate risk reduction strategies in the Swedish real estate portfolio using five different evaluation methods. The study is the first in its kind for the Swedish Real Estate market, and uses the total return series from MSCI Real Estate - IPD to calculate a pure return index for four property types, and four regions. The five evaluation methods are then applied to the pure index. The five methods, comparing: (1) correlation matrices, (2) efficient frontiers, (3) Sharpe ratios, (4) coefficients in equations explaining total returns and (5) $R^{2}$ values in equations explaining total returns, are, with one exception, the ones found in literature analysing risk reduction within the property portfolio. It is also the most ambitious attempt found in literature so far, to actually compare evaluation methods.

Diversification in a mean-variance context aims at removing unsystematic risk in an effort to minimize the fluctuations of a portfolio's return in excess of what the market will reward. Efficient portfolios are defined as the set of portfolios that achieve the lowest levels of risk for a given return or, alternatively, the highest level of return for a

* Corresponding author. E-mail: sigrid.katzler@abe.kth.se given level of risk. Markowitz (1952) was the first to discuss the concept of diversification through the formal development of modern portfolio theory (MPT). Originally developed for stocks and bonds, it took more than two decades until MPT was first applied to real estate. The Employee Retirement Income Security Act of 1974 in the US initiated research on the role of real estate in the multi asset portfolio. Once real estate was established as a legitimate core asset class, researchers turned their attention to diversification issues within the real estate portfolio.

The development of property return indices like the NCREIF and the IPD, made it possible to apply optimisation models to real estate return. The first paper to discuss diversification categories in real estate was written by Miles and McCue (1984) where they discussed factors like location, cash flow and lease and economic activity in the property area. Hartzell et al. followed in (1986) and covered property type, growth rate and lease maturity. A lot of other studies followed, for an overview of diversification issues in real estate investment see Seiler et al. (1999).

The idea behind risk reduction in a portfolio context is to maximize within group homogeneity 
while maximizing the heterogeneity between groups. While stocks are grouped primarily by market value and industry, real estate varies by property type, region (regions can be either geographic or economic, the latter indicating a grouping based on economic drivers), size (square footage and value) and distance to a city centre among other things. Out of these groups, property type and region are most commonly used in the real estate industry. This is because different market and macroeconomic factors are likely to influence property performance at the property type and regional level.

It could be argued that investing in combinations of property types and regions would result in efficient frontiers with higher return and/or less risk than only diversifying over property type or region. Viezer (2000) finds that combining four regions with four property types (resulting in sixteen groups) is the overall most efficient strategy compared to different combinations of property types, geographical and economic regions. However, investing in real estate is very costly. Thus, only the largest investor could afford to hold the amount of property necessary for that kind of strategy. It is therefore of great interest to an investor to know if grouping real estate by property type or region is the most efficient strategy when it comes to risk reduction.

Eichholtz et al. (1995) investigated the effectiveness of the diversification strategies grouping by property type and region for both Great Britain and the USA. On the British market, the difference between the two strategies was not statistically significant. On the US market, geographic regions showed a greater potential for risk reduction. Olaleye et al. (2008), studied the Nigerian market and came to the same conclusion.

However, most other studies indicate that property type grouping is more important as a risk diversifier, see for instance Lee and Byrne (1998), Fisher and Liang (2000), Lee (2001), and Gabrielli and Lee (2009).

The region classification scheme can be taken a step further by removing arbitrary geographic boundaries and looking at local economic drivers thereby linking markets across economic rather than spatial factors. Hartzell, et al. (1987) were the first to do this in the US real estate market when they divided it in eight functional regions using economic base. Malizia and Simons (1991) refined their analysis by using demand side factors such as unemployment, income and population. Mueller and Ziering (1992) compared the standard geographic categories East, Midwest, West and South with the categories invented by Hartzell et al. (1987) and added two of their own; one category that groups the US by dominant employment category and one by growth in employment rates. Other categories investigated are SIC (standard industrial classification), see Mueller (1993), and socio-economic e.g. crime rate and temperature, see Ziering and Hess (1995). For a more recent study, see Heydenreich (2010) who compares the traditional approach based on administrative regions to an economic strategy based on industry specialization in the UK market. He finds that that strategies based on economic diversification show superior risk-adjusted returns. Byrne and Lee (2011) also study the UK market and use the mean absolute deviation portfolio optimisation model to compare the performance of conventional administrative regions with the performance of functional groups based on data from the 2001 census. They find that the functional groups provide greater risk reduction and argue that the underlying characteristics of such groups might be more insightful and acceptable to real estate portfolio managers.

Viezer (2000) argues the importance of using the same number of dimensions when comparing diversification strategies. This would separate the effects of the method from the effect of varying the number of dimensions. Also when using certain statistical tools like the Jennrichs test to compare correlation matrices it is necessary to compare the same number of dimensions. Viezer also finds that correlation coefficients are poor indicators of which diversification method would provide the best efficient frontier. The diversification method that produced the lowest correlations did not provide the best efficient frontier. The return/risk ratio on the other hand, was found "pivotal".

The Markowitz's modern portfolio theory is only justified for temporally stable correlations, if correlations are unstable over time; the resulting mean-variance optimal portfolios are likely to underperform. Co integration methods on the other hand, identify long-term relationships, and are robust to correlation instability. Tarbert (1998) uses the Johansen maximum likelihood procedure to determine the long-run diversification possibilities on the UK property market, and finds that sectoral and geographical diversification possibilities are more limited than previous studies have indicated. Gallo et al. (2013) create a globally diversified portfolio using co integration methods over 1992-2009. Their co integration inspired model outperforms the mean-variance optimized portfolio by $575-725$ basis points annually. 
Another fact to consider is that an appraisalbased return series like the IPD index, tend to be smoothed. That is, the variability of returns in the property market tends to be understated, leading to false assumptions about the attractiveness of property as an asset class compared to stocks and bonds. Smoothing comes primarily from two sources; infrequent transactions that forces appraisers to combine value indications from recent comparable sales with past information, and, from the fact that property values are appraised at different points in time during the calendar year and then averaged together to produce the index value. The most common method to de-smooth a property index was developed by Geltner (1993), and the method uncovers the true underlying property return series by applying a reverse filter:

$$
R_{t}^{u}=\frac{R_{t}^{*}-(1-\alpha) R_{t-1}^{*}}{\alpha},
$$

where: $R_{t}^{u}$ is the unobservable underlying property markets return series at time $t ; R_{t}^{*}$ is the observed appraisal based index return in year $t$, and $\alpha$ is a smoothing parameter between 0 and 1 . If no smoothing is present in the index, then $\alpha$ is equal to 1 . The smoothing parameter is defined for the property market as a whole, since the amount of smoothing is the same for different property types and regions. Smoothing is therefore only a problem when considering the attractiveness of property in mixed-asset portfolios, not - as in the present paper - when considering weights within the property portfolio. See Hoesli, et al. (2003) for an analysis of suggested property weights in institutional portfolios using de smoothed indices for the US, UK and Sweden.

The remaining paper begins with a motivation for the methods chosen, a description of how pure indices are calculated and an explanation of the five methods. This is followed by a description of the data and the market under study. In the result section, the effectiveness of different diversification strategies is calculated using the five methods. Finally the results are analysed and the quality of the different techniques discussed.

\section{METHOD}

\subsection{The choice of methods}

The five methods described below are the ones most commonly used in real estate literature when data is scarce. Three of the methods might be problematic however; method, (1), (2) and (3) rely heavily on unstable correlations, making them less than ideal for prediction purposes. One way to work around that problem would be to use cointegration methods instead to identify long term relationships. If different property types or regions are not co integrated over the longer term, then combining these property types or regions in a property portfolio would be a diversification strategy. Although relevant for this study, Co- integration analysis is not included among the methods chosen. To study long-run relationships in the real estate market, ideally, a few real estate cycles and different market contexts should be included. If a real estate cycle lasts for eight to ten years, then the inclusion of enough cycles would require a sample of forty to fifty years Brooks and Tsolacos (2010). MSCI Real Estate - IPD for Sweden has to date only 28 data points, and such a study is not yet possible.

The present paper focuses on methods for portfolio optimization. To do this, the property classification, i.e., by type and region, is taken as given. There are other ways to classify property, economic regions being a good example, where local economic drivers are used to classify regions rather than geographical boundaries. Although of practical relevance, such alternative classification schemes are beyond the scope of this paper.

\subsection{Pure indices}

The first problem to address is that the sector and regional indices are not pure in the sense that the average total return from a certain geographical region has a component stemming from the property distribution in that region. If the property composition in Stockholm is different from the index, part of the return will come from the dominant property type distribution and not regional factors. In the same way, if the regional distribution of a property type is different from that of the entire sample, part of the return will come from the regional distribution and not the property type.

It is possible to separate the regional effect from the property type effect using regression analysis. The conventional way would be to use dummy variables for all property types and regions leaving one property type and one region as a reference point. A more elegant method, first suggested by Heston and Rouwenhorst (1994), uses a restricted regression equation allowing all dummy variables to be included in the equation and setting the constant as the mean return of the entire sample. This technique was later applied to property type and 
regional return in the NCREIF index by Fisher and Liang (2000) and on the IPD by Lee (2001). It is also the technique used in this paper.

In order to separate property type performance from regional performance, the following model for the return, $R_{i t}$, on the $i^{\text {th }}$ property that belongs to region $j$ and property type $k$ is formulated:

$$
R_{i t}=\alpha_{t}+\beta_{j t} C_{j t}+\gamma_{k t} P_{k t}+e_{i t}
$$

In the model, $\alpha_{t}$ is a base level of return in pe$\operatorname{riod} t, \beta_{j t}$ is the regional effect, $\gamma_{k t}$ is the property type effect, and $e_{i t}$ is a property-specific disturbance. This model measures separate influences from property type and region, but rules out any interaction between them. The property type dummy, $P_{i k}$ is equal to one if property $i$ belongs to property type $k$ and zero otherwise, and a regional dummy $C_{i j}$ that is equal to one if property $i$ belongs to region $j$, and zero otherwise. For each period $t$, (1) can be rewritten as:

$$
\begin{gathered}
R_{i}=a+\beta_{1} C_{i 1}+\beta_{2} C_{i 2}+\beta_{3} C_{i 3}+b_{4} C_{i 4}+\gamma_{1} P_{i 1}+ \\
\gamma_{2} P_{i 2}+\gamma_{3} P_{i 3}+\gamma_{4} P_{i 4}+e_{i} .
\end{gathered}
$$

It is not possible to estimate equation (2) directly because of perfect multi-collinearity, i.e., the four regional and property type vectors add up to the unit vector.

We could solve this by choosing one property type and one region as a base case as mentioned above. Rather than arbitrarily choosing a region and a property type as a benchmark, it is possible to find out how each property type and region differs from the average property in the sample. This will be equal to measuring regional and property type effects relative to the average return on the Swedish real estate market.

To avoid over specification of the model, the following restriction has to be imposed for each period:

$$
\sum_{j=1}^{4} n_{j} \beta_{j}=0, \text { (4a) } \quad \sum_{k=1}^{4} m_{k} \gamma_{k}=0,
$$

where: $n_{j}$ and $m_{k}$ stands for the number of properties in region $j$ and property type $k$ respectively. For an equal weighted index the constant $\alpha_{t}$ will equal the average equal weighted index for year $t$.

The pure regional return $\hat{\alpha}+\hat{\beta}_{j}$ is the leastsquares estimate of the return on a property type diversified portfolio in the $j^{\text {th }}$ region. To summarize, this means that a property type diversified portfolio has the same property type composition as the equally weighted property index.

By using a similar exercise, the value weighted return index is decomposed by estimating equa- tion (2) using weighted least squares. The weights are the average market values of the properties at year $t$ and the equation restrictions now become:

$$
\sum_{j=1}^{4} w_{j} \beta_{j}=0, \text { (5a) } \quad \sum_{k=1}^{4} v_{k} \gamma_{k}=0,
$$

where: $w_{j}$ and $v_{k}$ are the value weights of region $j$ and property type $k$ in the value weighted property index. As above $\sum w_{j}=\sum v_{k}=1$. Under these restrictions, the weighted least-squares estimate of the regression intercept $\alpha_{t}$ now becomes the average return of the value-weighted property index.

Equation (2) then becomes:

$R=\alpha+\beta_{1} \cdot$ Geo $1+\beta_{2} \cdot$ Geo $2+\beta_{3} \cdot$ Geo $3+\beta_{4} \cdot$ Geo $4+$

$\gamma_{1} \cdot$ Retail $+\gamma_{2} \cdot$ Office $+\gamma_{3} \cdot$ Industry $+\gamma_{4} \cdot$ Housing $+\varepsilon$.

The restricted equation for the equal weighted index will equal:

$$
\begin{aligned}
& R=\alpha+\frac{-n_{2} \times \beta_{2}-n_{3} \times \beta_{3}-n_{4} \times \beta_{4}}{n_{1}} \times G e o_{1}+\beta_{2} \times \\
& G e o_{2}+\beta_{3} \times G e o_{3}+\beta_{4} \times G e o_{4}+ \\
& \frac{-m_{2} \times y_{2}-m_{3} \times y_{3}-m_{4} \times y_{4}}{m_{1}} \times \text { Retail }+y_{2} \times \text { Office }+
\end{aligned}
$$

$y_{3} \times$ Industry $+y_{4} \times$ Housing $+\varepsilon$,

where: $m_{1}$ is the number of retail properties; $m_{2}$ is the number of office properties; $m_{3}$ is the number of industry properties; $m_{4}$ is the number of housing properties; $n_{1}$ is the number of properties located in Geo1; $n_{2}$ is the number of properties located in Geo2; $n_{3}$ is the number of properties located in Geo3 and $n_{4}$ is the number of properties located in the Geo4.

The regression above produces regional and property type effects for the year $t$. By running a cross sectional regression every year a time series of property type diversified regional returns $\hat{\alpha}+\hat{\beta}_{j t}$ and of regionally diversified property returns $\hat{\alpha}+\hat{\gamma}_{k t}$ is created.

\subsection{Correlation matrices}

The pure indices created above are used to calculate cross correlations between property type return and regional return. The average correlation coefficients for the different strategies are then compared. If the correlation coefficients between property type return are lower than those between regional return, this implies that property type diversification is a more efficient mean of reducing risk than using regions.

The Jennrich test was used for a formal comparison of correlation matrices (Jennrich 1970). It is used both for comparison between correlation 
matrices and to test if the correlation matrices are statistically different from the unity matrix.

The Jennrich test statistic for equality tests of correlation matrices has $p(p-1) / 2$ degrees of freedom, where $p$ is the dimension of the correlation matrix. The statistic is:

$$
\chi^{2}=0.5 \cdot \operatorname{tr}\left(Z^{2}\right)-\operatorname{diag}^{\prime}(Z) S^{-1} \operatorname{diag}(Z),
$$

where:

$$
Z=c^{1 / 2} C^{-1}\left(C_{1}-C_{2}\right) /\left(d_{1}+d_{2}\right)
$$

with $C_{1}$ and $C_{2}$ being the correlation matrices to be compared, and:

$$
C=\left(d_{1} C_{1}+d_{2} C_{2}\right) /\left(d_{1}+d_{2}\right)
$$

with $d_{1}$ and $d_{2}$ being the number of observations on which the matrices are based.

\subsection{Efficient frontier}

The efficient frontier for a property market is calculated using expected return, standard deviation and the correlation between property types or regions for instance. With quadratic programming, the different combinations of properties that lie on the efficient frontier are calculated. Each portfolio along the efficient frontier of a particular diversification strategy will be compared to every portfolio along the efficient frontier of a different strategy. The frontiers may be plotted, typically with the expected return on the vertical axis and the standard deviation on the horizontal axis. If the efficient frontier of one strategy is above and to the left of the other frontier, the first strategy dominates the other (it has higher return and / or lower risk).

\subsection{Sharpe ratios}

The above method becomes difficult to interpret when the two frontiers cross each other. It could be that one of the strategies is more efficient at low risk levels and that the other is more efficient at high levels of risk. It could also be difficult to determine if the difference between two frontiers is significant by just a visual inspection. Sharpe (1964) introduced the concept that a portfolio's risk return characteristics can be measured by its Sharpe ratio defined as excess return per unit of risk where $r_{t}$ is the portfolio return, $r_{f}$ is the riskfree rate of return and $d$ is the standard deviation of the portfolio. $S=\frac{r_{t}-r_{f}}{\delta_{t}}$.

Different performance measures have been developed to compare a portfolios' performance in some period relative to another period, or to compare different portfolios in the same period.
Jobson and Korkie (1981) discuss different comparison measures based on the traditional Sharpe and Treynor measures, evaluate them in small samples, and find that the Sharpe $\mathrm{z}$ statistic is well behaved for single comparisons although the power of the test is quite sensitive to the population's coefficient of variation. In Jobson and Korkie (1982), the analysis is refined and they identify two likelihood ratio statistics $\chi^{2}$ and an $F$-statistic suitable for small samples. Gibbons et al. (1989) continue the work to find suitable test statistics. Among other things they refine the Wald test, transforming it into an F-distribution and giving it a geometric interpretation for Sharpe ratios. This F-statistic is later used by Cheng and Liang (2000) to compare Sharpe ratios for different portfolios.

Following in the footsteps of Gibbons et al. (1989) we perform an F-test, a Lagrange multiplier test (LMT) and a likelihood ratio test (LRT) on the differences in Sharpe ratios.

The null hypothesis is that the Sharpe ratios of the two portfolios are equal and thus that they are equally efficient i.e. $H o: S_{1}=S_{2}$. We test this hypothesis using the following test statistic called the $W$ - statistic:

$$
W=\left[\frac{\sqrt{1+S_{1}^{2}}}{\sqrt{1+S_{2}^{2}}}\right]-1 .
$$

Large $W$ will lead to a rejection of the null hypothesis leading to the conclusion that there is a significant difference between the two portfolios. Since $W$ follows an uncommon Wishart distribution, it has to be converted into an $F$-distribution using the following expression:

$$
F=\frac{T(T-N-1)}{N(T-2)} \cdot W
$$

where: $T$ is the number of observations in a time series, and $N$ is the number of investment opportunities.

The other two test statistics, LRT and LMT are monotonic functions of $\mathrm{W}$, where $\mathrm{LRT}=\mathrm{T} \ln (1+\mathrm{W})$ and $\mathrm{LMT}=\mathrm{TW} /(1+\mathrm{W})$.

\subsection{Coefficient size and $\boldsymbol{R}^{2}$}

Calculating the pure indices as above, it is possible to test yearly for where the return in excess or below market return comes from. That is, the relative importance of the property type and regional effects. This is done by comparing the absolute average value of the property type and regional coefficients from the restricted regression in (6). A $T$-test is used to test for equalities of means. 
Another way to establish the relative importance of property type and regional factors is to calculate how much of the variation around the mean return that they explain i.e. to perform a simple linear regression with total return as the dependent variable and either property type or region as the independent variables. The way to rank the two strategies thus amounts to compare $R^{2}$ values using a $T$-test as above.

Both of the above tests are used by Lee (2001) although he only compares the levels of the coefficients without a formal $T$-test.

\section{DATA}

\subsection{Data distribution}

All data in this study are used with the kind permission of MSCI Real Estate - IPD. The dataset comprises the entire Swedish database with 27933 individual property observations, and the calculations are based on yearly total return figures calculated by IPD where the capital base is capital employed. The way yearly return is calculated in this study differs from the IPD method and the regions chosen are not the ones used in the IPD index. The author of this study calculated both the standard index and the pure index used in the study. Any mistakes in analysing the database are the authors own.

The original Swedish index started in 1997 but has later been back-dated as far as 1984. Today it has coverage of about twenty eight per cent of the Swedish commercial property market and a market value of 270 billion SEK. The index reports among other things total returns based on external valuations.

For this study, the observations in the data bank have been grouped by four property types and in four regions. The property types are; retail, office, industry and housing. The four regions Geo 1-4 are; the county of Stockholm, the county of Gothenburg, the county of Malmoe and the rest of Sweden.

As can be seen from Table 1, the data points are unevenly spread across both property type and region. Housing is the dominant property type with $38.5 \%$ of the properties, and the region Rest of Sweden covers more than $40 \%$ of the observations, followed by Stockholm with $37.2 \%$.

Table 2 shows the geographical distribution of the property types. For example, $75 \%$ of the retail properties are located in Rest of Sweden. For the entire sample, $40.9 \%$ of the properties are located in Rest of Sweden, which means that there are on average more retail properties in Rest of Sweden than in the other regions.

Table 3 displays the property type distribution within the regions. From this it is obvious that the Stockholm region for instance have a higher share of offices compared to the index $(61.65 \%$ compared with $33.1 \%)$ and a lower share of retail properties (9.02\% compared to $26.1 \%)$.

Table 1. Databank distribution for 2012

\begin{tabular}{llllll}
\hline Property type & No & Fraction & Region & No & Fraction \\
\hline Retail & 280 & $26.1 \%$ & Stockholm & 399 & $37.2 \%$ \\
Office & 355 & $33.1 \%$ & Gothenburg & 92 & $8.6 \%$ \\
Industrial & 26 & $2.4 \%$ & Malmoe & 144 & $13.4 \%$ \\
Housing & 413 & $38.5 \%$ & Rest of Sweden & 439 & $40.9 \%$ \\
Total & 1074 & $100.00 \%$ & Total & 1074 & $100.00 \%$ \\
\hline
\end{tabular}

This table shows the databank distribution for property types and regions for the year 2012 .

Table 2. Geographical distribution of the property types

\begin{tabular}{llllllllll}
\hline Region & $\begin{array}{l}\text { Retail } \\
\text { No }\end{array}$ & Fraction & $\begin{array}{l}\text { Office } \\
\text { No }\end{array}$ & Fraction & $\begin{array}{l}\text { Industrial } \\
\text { No }\end{array}$ & Fraction & $\begin{array}{l}\text { Housing } \\
\text { No }\end{array}$ & Fraction & Total \\
\hline Stockholm & 36 & $12.86 \%$ & 246 & $69.30 \%$ & 6 & $23.08 \%$ & 111 & $26.88 \%$ & 399 \\
Gothenburg & 18 & $6.43 \%$ & 42 & $11.83 \%$ & 9 & $34.62 \%$ & 23 & $5.57 \%$ & 92 \\
Malmoe & 16 & $5.71 \%$ & 38 & $10.70 \%$ & 1 & $3.85 \%$ & 89 & $21.55 \%$ & 144 \\
Rest of Sweden & 210 & $75.00 \%$ & 29 & $8.17 \%$ & 10 & $38.46 \%$ & 190 & $46.00 \%$ & 439 \\
Total & 280 & $100.00 \%$ & 355 & $100.00 \%$ & 26 & $100.00 \%$ & 413 & $100 \%$ & 1074 \\
\hline
\end{tabular}

This table shows the geographical distribution of the property types in the databank for year 2012 . 
Table 3. Property type distribution of the regions

\begin{tabular}{|c|c|c|c|c|c|c|c|c|c|}
\hline Region & $\begin{array}{l}\text { Stockholm } \\
\text { No }\end{array}$ & Fraction & $\begin{array}{l}\text { Gothenburg } \\
\text { No }\end{array}$ & Fraction & $\begin{array}{l}\text { Malmoe } \\
\text { No }\end{array}$ & Fraction & $\begin{array}{l}\text { Rest of } \\
\text { Sweden } \\
\text { No }\end{array}$ & Fraction & Total \\
\hline Retail & 36 & $9.02 \%$ & 18 & $19.57 \%$ & 16 & $11.11 \%$ & 210 & $47.87 \%$ & 280 \\
\hline Office & 246 & $61.65 \%$ & 42 & $45.65 \%$ & 38 & $26.39 \%$ & 29 & $6.61 \%$ & 355 \\
\hline Industrial & 6 & $1.5 \%$ & 9 & $9.78 \%$ & 1 & $0.69 \%$ & 10 & $2.28 \%$ & 26 \\
\hline Housing & 111 & $27.82 \%$ & 23 & $25.00 \%$ & 89 & $61.81 \%$ & 190 & $43.28 \%$ & 413 \\
\hline Total & 399 & $100.00 \%$ & 92 & $100.00 \%$ & 144 & $100.00 \%$ & 439 & $100 \%$ & 1074 \\
\hline
\end{tabular}

This table shows the property type distribution of the regions in the databank for year 2012 .

\subsection{Measuring return}

There are normally two ways of measuring return, equal-weighted and value-weighted. In an equalweighted index all observations are given equal weight. In a value-weighted index all observations are weighted according to their market value. The IPD index is a value-weighted index. The advocates for a value weighted index argues that valueweighting gives a truer image of the market and that it is inappropriate to give observations with low market values the same importance as very valuable objects.

Others might argue that the only reason for giving one observation a higher weight would be if it were more reliable than another. Since there is no reason to expect the measured return in a small object to be less reliable than that of a large one an equal weighted index should be used. A deeper analysis of the weighting of return in real estate is beyond the scope of this paper and therefore all analyses are made both for a value-weighted and an equal-weighted index.

\section{RESULTS}

\subsection{Pure return}

The pure indices differ from the original indices. This was expected since the geographical distribution of property types and the property type distributions of the regions are different from the market as a whole. However, the differences are small. For example, the pure office return for the equal weighted return increases with approximately $1 \%$ compared to the original index as can be seen in Table 4.

\subsection{Cross correlations for different time periods}

For value weighted return, the average cross correlations between property types and regions are extremely high for the time period 1984-2012
Table 4. Average return and standard deviation of the original return measurement compared with pure return

\begin{tabular}{|c|c|c|c|c|}
\hline & $\begin{array}{l}\text { Pure } \\
\text { average } \\
\text { return }\end{array}$ & $\begin{array}{l}\text { Pure } \\
\text { stand- } \\
\text { ard de- } \\
\text { viation }\end{array}$ & $\begin{array}{l}\text { Original } \\
\text { average } \\
\text { return }\end{array}$ & $\begin{array}{l}\text { Origi- } \\
\text { nal } \\
\text { stand- } \\
\text { ard } \\
\text { devia- } \\
\text { tion }\end{array}$ \\
\hline \multicolumn{5}{|l|}{ Value weighted } \\
\hline Retail & $11.78 \%$ & $12.24 \%$ & $11.55 \%$ & $10.96 \%$ \\
\hline Office & $11.41 \%$ & $16.51 \%$ & $11.39 \%$ & $14.45 \%$ \\
\hline Industrial & $11.56 \%$ & $15.30 \%$ & $11.41 \%$ & $13.03 \%$ \\
\hline Housing & $14.54 \%$ & $13.41 \%$ & $14.43 \%$ & $10.75 \%$ \\
\hline Stockholm & $14.27 \%$ & $21.03 \%$ & $11.89 \%$ & $14.66 \%$ \\
\hline Malmoe & $14.60 \%$ & $18.46 \%$ & $12.88 \%$ & $11.50 \%$ \\
\hline Gothenburg & $14.28 \%$ & $17.73 \%$ & $12.18 \%$ & $11.22 \%$ \\
\hline Rest of Sweden & $10.70 \%$ & $10.18 \%$ & $11.06 \%$ & $9.66 \%$ \\
\hline \multicolumn{5}{|c|}{ Equally weighted } \\
\hline Retail & $11.43 \%$ & $13.66 \%$ & $11.21 \%$ & $12.79 \%$ \\
\hline Office & $11.72 \%$ & $12.09 \%$ & $10.68 \%$ & $13.88 \%$ \\
\hline Industrial & $11.55 \%$ & $10.84 \%$ & $10.64 \%$ & $11.67 \%$ \\
\hline Housing & $15.02 \%$ & $8.75 \%$ & $14.30 \%$ & $10.71 \%$ \\
\hline Stockholm & $14.41 \%$ & $18.90 \%$ & $12.16 \%$ & $13.27 \%$ \\
\hline Malmoe & $15.88 \%$ & $17.45 \%$ & $13.66 \%$ & $12.25 \%$ \\
\hline Gothenburg & $15.22 \%$ & $17.13 \%$ & $12.74 \%$ & $11.88 \%$ \\
\hline $\begin{array}{l}\text { Rest of Swe- } \\
\text { den }\end{array}$ & $10.62 \%$ & $9.90 \%$ & $10.25 \%$ & $10.60 \%$ \\
\hline
\end{tabular}

This table displays average return and standard deviation for the MSCI and the pure return index. The table includes both equally and value weighted indexes.

(see Table 5) with an average of $93.1 \%$ between property types and $95.0 \%$ between regions indicating that property types are slightly better as a diversifier. A plausible reason for the high correlations is the impact the crash on the real estate market in the beginning of the 1990s had on market return. If, for a few particular years, market return drops significantly and in unison for all property types and regions this will actually affect average cross correlations over time. 
Table 5. Cross correlations of value weighted returns for property types and regions

\begin{tabular}{|c|c|c|c|c|c|c|c|c|c|}
\hline & Retail & Office & Industrial & Housing & & Stockholm & Malmoe & $\begin{array}{l}\text { Gothen- } \\
\text { burg }\end{array}$ & $\begin{array}{l}\text { Rest of } \\
\text { Sweden }\end{array}$ \\
\hline \multicolumn{10}{|l|}{ 1984-2012 } \\
\hline Retail & 1 & & & & Stockholm & 1 & & & \\
\hline Office & 0.924 & 1 & & & Malmoe & 0.981 & 1 & & \\
\hline Industrial & 0.940 & 0.963 & 1 & & Gothenburg & 0.977 & 0.972 & 1 & \\
\hline Housing & 0.880 & 0.947 & 0.931 & 1 & Rest of Sweden & 0.925 & 0.925 & 0.922 & 1 \\
\hline Average & 0.931 & & & & Average & 0.950 & & & \\
\hline \multicolumn{10}{|l|}{ 1993-2012 } \\
\hline Retail & 1 & & & & Stockholm & 1 & & & \\
\hline Office & 0.681 & 1 & & & Malmoe & 0.950 & 1 & & \\
\hline Industrial & 0.750 & 0.851 & 1 & & Gothenburg & 0.964 & 0.954 & 1 & \\
\hline Housing & 0.480 & 0.818 & 0.708 & 1 & Rest of Sweden & 0.737 & 0.665 & 0.746 & 1 \\
\hline Average & 0.715 & & & & Average & 0.836 & & & \\
\hline
\end{tabular}

This table displays cross correlations between value weighted property type and regional return for the time-periods 1984-2012 and 1993-2012.

Table 6. Cross correlations of equal weighted returns for property types and regions

\begin{tabular}{|c|c|c|c|c|c|c|c|c|c|}
\hline & Retail & Office & Industrial & Housing & & Stockholm & Malmoe & Gothenburg & $\begin{array}{l}\text { Rest of } \\
\text { Sweden }\end{array}$ \\
\hline \multicolumn{10}{|l|}{ 1984-2012 } \\
\hline Retail & 1 & & & & Stockholm & 1 & & & \\
\hline Office & 0.816 & 1 & & & Malmoe & 0.969 & 1 & & \\
\hline Industrial & 0.717 & 0.873 & 1 & & Gothenburg & 0.966 & 0.944 & 1 & \\
\hline Housing & 0.718 & 0.837 & 0.838 & 1 & Rest of Sweden & 0.889 & 0.903 & 0.875 & 1 \\
\hline Average & 0.800 & & & & Average & 0.924 & & & \\
\hline \multicolumn{10}{|l|}{ 1993-2012 } \\
\hline Retail & 1 & & & & Stockholm & 1 & & & \\
\hline Office & 0.398 & 1 & & & Malmoe & 0.916 & 1 & & \\
\hline Industrial & 0.495 & 0.768 & 1 & & Gothenburg & 0.941 & 0.910 & 1 & \\
\hline Housing & 0.369 & 0.738 & 0.633 & 1 & Rest of Sweden & 0.662 & 0.582 & 0.562 & 1 \\
\hline Average & 0.567 & & & & Average & 0.762 & & & \\
\hline
\end{tabular}

This table displays cross correlations between equal weighted property type and regional return for the time-periods 1984-2012 and 1993-2012.

In order to investigate this, an alternative correlation matrix was calculated for the time period 1993-2012, starting after market recovery. The correlations drop significantly to $71.5 \%$ and $83.6 \%$ respectively indicating that the crash indeed is part of the explanation.

Equal weighted return cross correlations for the full time-period are a little lower than the cross correlations for the value weighted index (see Table 6), with $80 \%$ for property types and $92.4 \%$ for regions. For the time period 1993-2012 the correlations are $56.7 \%$ and $76.2 \%$ and the difference between weighting schemes are almost $15 \%$ for property type and $7.4 \%$ for region. This is consistent with a study by Schuck and Brown (1997) who compare value-weighting and equal-weighting in terms of risk reduction and find that value-weighting leads to increased specific risk.

\subsection{Comparison of correlation matrices}

To formally compare the two correlation matrices calculated for property type and region we use the Jennrich statistic described in 2.3 , where the difference between every entity in the matrices is calculated, not just the average. The Jennrichs statistic follows an $\chi^{2}$-distribution and the null hypothesis is that the matrices are equal. The critical $\chi^{2}$-value for six degrees of freedom at the 0.05 level is 12.6 , and 10.645 at the 0.1 level. As can be seen in Table 7, the null hypothesis can only be rejected for the equal-weighted index, not for the value-weighted index. 
All four correlation matrices are statistically different from the unity matrix at the 0.05 level, meaning that the hypothesis of perfect correlation between property types and regions can be rejected.

Table 7. Jennrich test for comparing equality of matrices

\begin{tabular}{ll}
\hline & $\begin{array}{l}\text { Regional correlation } \\
\text { matrix }\end{array}$ \\
\hline $\begin{array}{l}\text { Value weighted } \\
\text { Property type correlation matrix }\end{array}$ & 8.77 \\
$\begin{array}{l}\text { Equal weighted } \\
\text { Property type correlation matrix }\end{array}$ & 11.63 \\
\hline
\end{tabular}

This table displays results of the Jennrichs test for the equality of two correlation matrices. The comparisons are between the property type and regional correlation matrices.

\subsection{Comparison of efficient frontiers}

In Figure 1 the efficient frontiers for value- and equally-weighted portfolios are displayed in the same graph. It is obvious that equal weighting is superior to value weighting in terms of risk reduction, a finding consistent with the difference in average cross correlations.

As for the most efficient strategy, it is clear that diversifying over property type is more efficient than diversifying over region; this is true for both the value-weighted and the equal-weighted return series. For the value-weighted portfolio, an investor who diversified over property type got more than $5 \%$ higher return than an investor investing in the regional portfolio at the same level of risk.

Diversifying over property type while using an equal weighted return series makes the efficient frontier boil down to one single point, namely a $100 \%$ investment in housing. This is not strictly true since a frontier will always be the result of the optimisation process but the allocation to other property types is so small that it falls under the margin of error. The

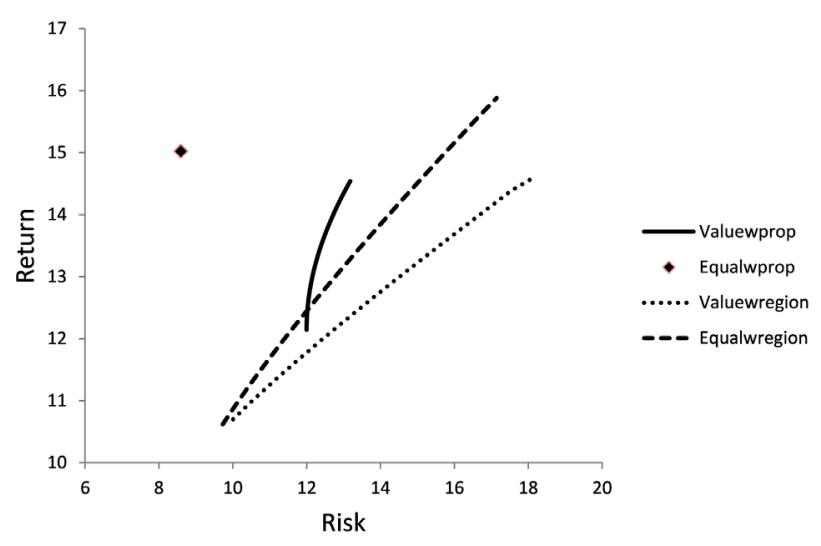

Fig. 1. The efficient frontier for equal- and value-weighted portfolios
Table 8. Portfolio weightings for twenty points on the efficient frontier for value- and equal-weighted property type portfolios

\begin{tabular}{lrllll}
\hline Risk & Return & Retail & Office & Industrial & Housing \\
\hline \multicolumn{4}{l}{ lalue-weighted } \\
12.00 & 12.14 & 0.87 & 0.00 & 0.00 & 0.13 \\
12.00 & 12.27 & 0.82 & 0.00 & 0.00 & 0.18 \\
12.01 & 12.39 & 0.78 & 0.00 & 0.00 & 0.22 \\
12.03 & 12.52 & 0.73 & 0.00 & 0.00 & 0.27 \\
12.05 & 12.65 & 0.69 & 0.00 & 0.00 & 0.31 \\
12.08 & 12.77 & 0.64 & 0.00 & 0.00 & 0.36 \\
12.12 & 12.90 & 0.60 & 0.00 & 0.00 & 0.40 \\
12.16 & 13.03 & 0.55 & 0.00 & 0.00 & 0.45 \\
12.21 & 13.15 & 0.50 & 0.00 & 0.00 & 0.50 \\
12.27 & 13.28 & 0.46 & 0.00 & 0.00 & 0.54 \\
12.34 & 13.41 & 0.41 & 0.00 & 0.00 & 0.59 \\
12.41 & 13.53 & 0.37 & 0.00 & 0.00 & 0.63 \\
12.48 & 13.66 & 0.32 & 0.00 & 0.00 & 0.68 \\
12.56 & 13.78 & 0.27 & 0.00 & 0.00 & 0.73 \\
12.65 & 13.91 & 0.23 & 0.00 & 0.00 & 0.77 \\
12.75 & 14.04 & 0.18 & 0.00 & 0.00 & 0.82 \\
12.85 & 14.16 & 0.14 & 0.00 & 0.00 & 0.86 \\
12.95 & 14.29 & 0.09 & 0.00 & 0.00 & 0.91 \\
13.06 & 14.42 & 0.05 & 0.00 & 0.00 & 0.95 \\
13.18 & 14.54 & 0.00 & 0.00 & 0.00 & 1.00 \\
Equal weighted & & & & \\
8.60 & 15.02 & & & & \\
\hline
\end{tabular}

This table displays risk, return and portfolio weightings for portfolios on the efficient frontier.

reason for this is that housing has one of the highest returns and by far the lowest risk of all property types when the return series is equal weighted. As can be seen from Table 8, investing only in housing gave an expected return of $15.02 \%$, and an expected risk of $8.6 \%$ for the equal-weighted portfolio. For the value weighted portfolios, the low risk portfolio consisted of almost $87 \%$ in retail, and the rest in housing. For higher risk portfolios, housing was gradually introduced into the portfolio. The high risk portfolio consisted of housing only; with an expected return of $14.54 \%$ and an expected risk of $13.18 \%$.

Diversifying the investments over regions gave the portfolio weightings displayed in Table 9. For the value-weighted portfolio with the lowest risk level the investment was in the rest of Sweden only. The high risk portfolio comprised of investments in the county of Malmoe. It is always the case that the efficient portfolio with the highest risk level solely consists of the property type or region with the highest return regardless of how much additional risk that is taken. The high risk portfolio provided an additional $0.2 \%$ return and 
an additional $0.6 \%$ higher risk compared to the portfolio above, consisting of equal investments in Malmoe and Gothenburg. The region of Stockholm was never included in the portfolio.

The equal-weighted portfolios were basically the same except for a smaller inclusion of the region of Gothenburg in the portfolios with average risk and return.

Table 9. Portfolio weightings for twenty points on the efficient frontier for value- and equal-weighted region portfolios

\begin{tabular}{|c|c|c|c|c|c|}
\hline Risk & Return & Stockholm & Malmoe & $\begin{array}{l}\text { Goth- } \\
\text { enburg }\end{array}$ & $\begin{array}{l}\text { Rest of } \\
\text { Sweden }\end{array}$ \\
\hline \multicolumn{6}{|c|}{ Value-weighted } \\
\hline 10.01 & 10.70 & 0.00 & 0.00 & 0.00 & 1.00 \\
\hline 10.36 & 10.91 & 0.00 & 0.00 & 0.06 & 0.94 \\
\hline 10.73 & 11.11 & 0.00 & 0.00 & 0.11 & 0.89 \\
\hline 11.11 & 11.32 & 0.00 & 0.01 & 0.16 & 0.83 \\
\hline 11.50 & 11.52 & 0.00 & 0.05 & 0.18 & 0.77 \\
\hline 11.90 & 11.73 & 0.00 & 0.08 & 0.20 & 0.72 \\
\hline 12.30 & 11.93 & 0.00 & 0.11 & 0.22 & 0.67 \\
\hline 12.72 & 12.14 & 0.00 & 0.14 & 0.25 & 0.61 \\
\hline 13.14 & 12.34 & 0.00 & 0.17 & 0.27 & 0.56 \\
\hline 13.56 & 12.55 & 0.00 & 0.21 & 0.29 & 0.50 \\
\hline 13.99 & 12.75 & 0.00 & 0.24 & 0.32 & 0.45 \\
\hline 14.42 & 12.96 & 0.00 & 0.27 & 0.34 & 0.39 \\
\hline 14.86 & 13.16 & 0.00 & 0.30 & 0.36 & 0.34 \\
\hline 15.30 & 13.37 & 0.00 & 0.33 & 0.38 & 0.28 \\
\hline 15.75 & 13.57 & 0.00 & 0.36 & 0.41 & 0.23 \\
\hline 16.20 & 13.78 & 0.00 & 0.40 & 0.43 & 0.18 \\
\hline 16.65 & 13.98 & 0.00 & 0.43 & 0.45 & 0.12 \\
\hline 17.10 & 14.19 & 0.00 & 0.46 & 0.47 & 0.07 \\
\hline 17.56 & 14.39 & 0.00 & 0.49 & 0.50 & 0.01 \\
\hline 18.14 & 14.60 & 0.00 & 1.00 & 0.00 & 0.00 \\
\hline \multicolumn{6}{|c|}{ Equal-weighted } \\
\hline 9.73 & 10.62 & 0.00 & 0.00 & 0.00 & 1.00 \\
\hline 10.04 & 10.90 & 0.00 & 0.04 & 0.02 & 0.95 \\
\hline 10.36 & 11.17 & 0.00 & 0.09 & 0.02 & 0.89 \\
\hline 10.70 & 11.45 & 0.00 & 0.13 & 0.03 & 0.84 \\
\hline 11.05 & 11.73 & 0.00 & 0.18 & 0.03 & 0.79 \\
\hline 11.40 & 12.00 & 0.00 & 0.23 & 0.04 & 0.73 \\
\hline 11.77 & 12.28 & 0.00 & 0.28 & 0.04 & 0.68 \\
\hline 12.15 & 12.56 & 0.00 & 0.33 & 0.05 & 0.63 \\
\hline 12.54 & 12.83 & 0.00 & 0.37 & 0.05 & 0.57 \\
\hline 12.93 & 13.11 & 0.00 & 0.42 & 0.06 & 0.52 \\
\hline 13.33 & 13.39 & 0.00 & 0.47 & 0.07 & 0.47 \\
\hline 13.73 & 13.67 & 0.00 & 0.52 & 0.07 & 0.41 \\
\hline 14.14 & 13.94 & 0.00 & 0.56 & 0.08 & 0.36 \\
\hline 14.56 & 14.22 & 0.00 & 0.61 & 0.08 & 0.31 \\
\hline 14.98 & 14.50 & 0.00 & 0.66 & 0.09 & 0.25 \\
\hline 15.40 & 14.77 & 0.00 & 0.71 & 0.09 & 0.20 \\
\hline 15.83 & 15.05 & 0.00 & 0.76 & 0.10 & 0.15 \\
\hline 16.26 & 15.33 & 0.00 & 0.80 & 0.10 & 0.09 \\
\hline 16.69 & 15.60 & 0.00 & 0.85 & 0.11 & 0.04 \\
\hline 17.14 & 15.88 & 0.00 & 1.00 & 0.00 & 0.00 \\
\hline
\end{tabular}

This table displays risk, return and portfolio weightings for portfolios on the efficient frontier.

\subsection{Comparison of Sharpe ratios}

For both the value weighted and the equal weighted index, the property type strategy is clearly superior to diversifying over regions (see Table 10). The result of the F-test described in 2.4 is 1.93 for value-weighted portfolios and 6.37 for equalweighted portfolios. The critical $F$-value at the 5 per cent level is 1.86 . This means that the null hypothesis assuming equal Sharpe ratios can be rejected for equal and value-weighted portfolios both.

The likelihood ratio statistic has a value of 7.81 for the value weighted index, and a value of 20.26 for the equal weighted index. The critical $\chi^{2}$ value at the 5 per cent level is 7.815 , meaning that the null hypothesis assuming equal Sharpe ratios can be rejected for equal weighted portfolios. At the 10 percent level, the null hypothesis can be rejected for value weighted portfolios as well.

The Lagrange multiplier test statistic has a value of 6.82 for the value weighted index, and a value of 14.42 for the equal weighted index, meaning that the null hypothesis assuming equal Sharpe ratios can be rejected for equal weighted portfolios. As for the likelihood ratio statistic, at the 10 percent level the null hypothesis can be rejected for the value weighted portfolio as well.

Table 10. Risk, return and Sharpe ratios for regionally and property type diversified portfolios

\begin{tabular}{lccl}
\hline & Risk & Return & $\begin{array}{l}\text { Sharpe } \\
\text { ratio }\end{array}$ \\
\hline $\begin{array}{l}\text { Value weighted } \\
\begin{array}{l}\text { Regionally diversified } \\
\text { portfolio }\end{array}\end{array}$ & 18.140 & 14.598 & 0.760 \\
$\begin{array}{l}\text { Property type portfolio } \\
\text { Equal weighted }\end{array}$ & 13.179 & 14.543 & 1.041 \\
$\begin{array}{l}\text { Regionally diversified } \\
\text { portfolio }\end{array}$ & 15.828 & 15.051 & 0.899 \\
Property type portfolio & 8.598 & 15.021 & 1.652 \\
\hline
\end{tabular}

This table displays risk return and Sharpe ratios for pair wise equal risk levels for value weighted and equal weighted portfolios.

\subsection{Comparison of coefficient sizes}

In the regression used for creating the pure indices the average absolute coefficient size for the independent variables is calculated, see Table 11.

The null hypothesis is that the two population means are equal, and the $T$-test involves finding the probability of observing a $t$ statistic at least as extreme as the one calculated from the data, assuming the null hypothesis is true. With 6 degrees of freedom, the critical $t$-statistic is 2.45 for $\alpha=$ 0.05 , and 1.94 for $\alpha=0.1$. 
Table 11. Absolute average values of property type- and regional coefficients

\begin{tabular}{|c|c|c|c|c|c|c|c|c|c|}
\hline Retail & Office & Industrial & Housing & $\begin{array}{l}\text { Avg. for } \\
\text { property } \\
\text { type }\end{array}$ & Stockholm & Malmoe & Gothenburg & $\begin{array}{l}\text { Rest of } \\
\text { Sweden }\end{array}$ & $\begin{array}{l}\text { Avg. for } \\
\text { region }\end{array}$ \\
\hline \multicolumn{10}{|c|}{ Value weighted } \\
\hline 1.65 & 4.08 & 3.09 & 4.43 & 3.31 & 6.92 & 5.19 & 4.97 & 2.98 & 5.02 \\
\hline \multicolumn{10}{|c|}{ Equal weighted } \\
\hline 2.13 & 4.54 & 5.96 & 6.29 & 4.73 & 6.88 & 6.13 & 6.09 & 2.74 & 5.46 \\
\hline
\end{tabular}

This table displays the absolute average values of different property type and regional coefficients for the value weighted and the equal weighted coefficients.

Table 12. Test for equality of means between coefficient types

\begin{tabular}{lcccccc}
\hline & Mean & Std. Deviation & $\mathrm{F}$ & $\mathrm{Sig}$. & $\mathrm{t}$ & $\mathrm{df}$ \\
\hline $\begin{array}{l}\text { Value weighted } \\
\text { Property type }\end{array}$ & 3.31 & 1.25 & 0.024 & 0.882 & 1.678 & 6 \\
$\begin{array}{l}\text { Region } \\
\text { Equal weighted }\end{array}$ & 5.01 & 1.61 & & & & \\
$\begin{array}{l}\text { Property type } \\
\text { Region }\end{array}$ & 4.73 & 1.90 & 0.003 & 0.962 & 0.552 & 6 \\
\hline
\end{tabular}

This table displays means and standard deviations of the absolute values of property type and regional coefficients. The table also shows the result of a t-test for the equality of means.

From Table 12 we see that none of the $t$-statistics are significant at either level meaning the null hypothesis of equal coefficient sizes cannot be rejected. Although the coefficient for region is higher for both the equal and the value weighted index, the difference is not statistically significant.

\subsection{Comparison of $R^{2}$ values}

In the regression used for calculating the pure indices the average $R^{2}$ value over time is calculated. The values are displayed in Table 13 together with the results from the $T$-test for equalities of means. The $R^{2}$ values are higher for the regression using property types as compared to using regions as dependent variables. With 56 degrees of freedom, the critical $t$-statistic is 2.0 for $\alpha=0.05$, and 1.67 for $\alpha=0.1$.
This means that the null hypothesis of equality of means can be rejected for the comparisons of equal weighted regressions. For the value weighted regression, the difference between $R^{2}$ values is not statistically significant.

\subsection{Comparing the methods and the strategies}

Above, we have studied two possible portfolio diversification strategies, one based on property type and one based on region. The strategies are applied to both a value weighted and an equally weighted index. To evaluate which strategy is best, we have employed five different tests. With the exception of a co integration test, for which we do not have sufficient data, these five tests are the ones that typically are used for studying diversification

Table 13. Test for equality of means between $\mathrm{R}$ square values

\begin{tabular}{lllllll}
\hline & Mean & Std. Deviation & F & Sig. & t & df \\
\hline $\begin{array}{l}\text { Value weighted } \\
\text { Property type }\end{array}$ & 0.050 & 0.059 & 6.885 & 0.011 & 0.728 & 56 \\
$\begin{array}{l}\text { Region } \\
\text { Equal weighted }\end{array}$ & 0.040 & 0.037 & & & & \\
Property type & 0.046 & 0.043 & \multirow{2}{*}{17.95} & 0 & 5.477 \\
Region & 0.024 & 0.016 & & & 56 \\
\hline
\end{tabular}

This table displays means and standard deviations of the R-square values for the simple linear regressions with total return as the dependent variable and either a set of dummies for property types or regions as independent variables. The table also shows the result of a t-test for the equality of means. 
within a property portfolio. However, in the earlier literature, it is rarely the case that all tests are used in any given study. Rather, the earlier studies tend to use just one or a few of the tests that we employ here. One important contribution with the present study is thus that we may compare the outcome of the tests.

The results are summarized in Table 14. The table reveals several interesting conclusions. First, it is clearly the case that, if any, property type provides the best basis for diversification in the Swedish context. There is not any test, either using value weighted or equally weighted indices, which provides support for using the regional classification as diversification base. The coefficient size test favours regions, but the results are not significant. Thus, it is not possible to draw any conclusions regarding which strategy is better using this test.

Second, the equally weighted index provides stronger results regarding which strategy is best. For the value weighted index, only the Sharpe ratios test shows a significant difference between the strategies. For the equally weighted index however, the correlation test and the R-square test also gives support for the property type approach being preferred on significant levels of 0.1 or less. This does not necessarily imply that equally weighted indices are to be preferred to value weighted indices - only that it, in this case, provides stronger results.

Table 14. A comparison of methods

\begin{tabular}{|c|c|c|}
\hline & Best strategy & $\begin{array}{l}\text { Statistical signifi- } \\
\text { cance }\end{array}$ \\
\hline \multicolumn{3}{|l|}{ Value weighted } \\
\hline Correlations & Property type & Not significant \\
\hline Efficient frontiers & Property type & Not applicable \\
\hline \multicolumn{3}{|l|}{ Sharpe ratios } \\
\hline F-test & Property type & At the 0.05 level \\
\hline LRT & Property type & At the 0.1 level \\
\hline LMT & Property type & At the 0.1 level \\
\hline Coefficient size & Region & Not significant \\
\hline $\mathrm{R}$-square values & Property type & Not significant \\
\hline \multicolumn{3}{|l|}{ Equal weighted } \\
\hline Correlations & Property type & At the 0.1 level \\
\hline Efficient frontiers & Property type & Not applicable \\
\hline \multicolumn{3}{|l|}{ Sharpe ratios } \\
\hline F-test & Property type & At the 0.05 level \\
\hline $\mathrm{LRT}$ & Property type & At the 0.05 level \\
\hline LMT & Property type & At the 0.05 level \\
\hline Coefficient size & Region & Not significant \\
\hline $\mathrm{R}$-square values & Property type & At the 0.05 level. \\
\hline
\end{tabular}

This table displays the best diversification strategies according to the different evaluation methods and their statistical significance.

\section{DISCUSSION}

\subsection{The dominance of housing}

It seems that housing singles out in terms of its risk/return ratio, and is therefore worth some discussion. The market for multifamily housing in Sweden is under regulation, and the rent regulation system is based on collective negotiation between local property owners and the local tenant union. In reality the local tenant union has strong bargaining power and the result is a system where rents in the older stock have followed inflation while rents in new production are set in order to cover costs. This implies more market oriented rents in new construction but rents far below the market level in the old housing stock in central locations. In the absence of market rents, attractive areas have very low vacancies. For a more thorough discussion see Elsinga and Lind (2013). As a consequence, the income stream for property owners investing in housing will be very stable, and will not fluctuate as much as the income from other property types. Figure 2 shows how the housing return follows the return from other property types but typically at lower amplitude. Most striking is the recession in the beginning of the nineties where the drop in housing return is much smaller than for the other property types.

In the housing market, especially in Stockholm, it has been more profitable for the owners of multi-family houses with rental apartments to sell to tenant associations wanting to transform the property to housing co-ops than to other investors.

The prices the tenant associations are willing to pay is expected to end up some halfway between the market value of all the individual apartments and the price a property investor would pay to keep it in its present form. The price level of coop apartments rose with around $50 \%$ in nominal

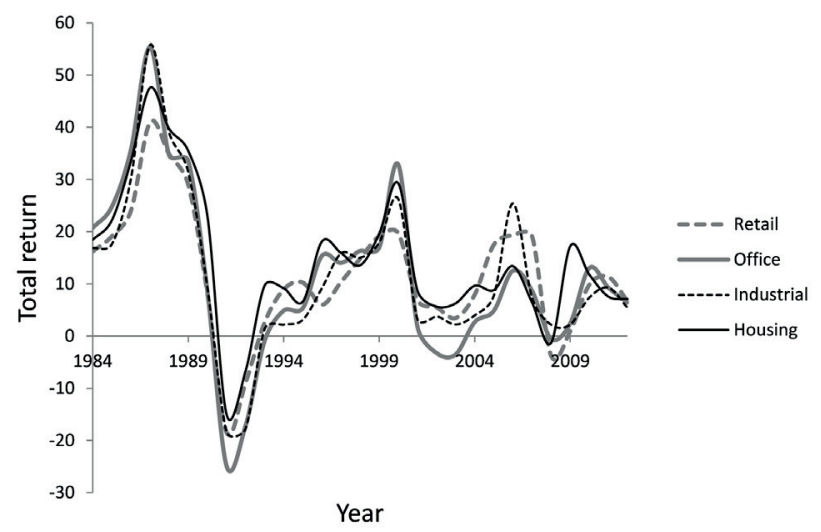

Fig. 2. The pure value-weighted index for different property types 
terms between 1990 and 2004 and the price difference when selling to housing co-ops compared to selling to another investor were substantial. Not only has this had a large impact on capital return for houses transformed to co-ops, valuers expect the elevated price levels to spill over on ordinary transactions as well.

The number of co-ops in the city of Stockholm has gone from $29 \%$ of the apartments to $60 \%$ between the years 1990 and 2012. There is uncertainty about if the transformation will continue. In 2002 , the government introduced a law that made it more difficult for municipalities to sell their multi-family houses to private investors and the City of Stockholm introduced a policy to prevent public housing companies in the city to sell their houses to co-ops. The private house owners on the other hand continue to transform their properties.

\subsection{High correlation between portfolios}

Average cross correlations between property types and regions are fairly high for the investigated time period, and part of the explanation might be that the Swedish real estate market is small and homogeneous from an international perspective. Another explanation might be the behaviour of Swedish valuers. The Swedish consultancy market is dominated by four valuation companies who basically all have the same market information, see e.g. Nordlund (2004). This might lead to that valuers are reluctant to deviate from what is considered common knowledge. It also seems that Swedish valuers do not distinguish much between different regions when it comes to setting discount rates. In his study, Nordlund also finds that Swedish valuers tend to ignore differences in local municipality fees.

In the year $2002,43 \%$ of the properties had mixed use (properties that have rentable areas for both housing and for commercial purposes). The dominating use according to market value will determine the property's classification in the index. This might result in properties changing classification during the index period. If there were a way of separating the total return of a mixed use property, the correlation between property types would probably lessen to some extent.

\section{CONCLUSIONS}

The purpose of this study was to compare the effectiveness of different diversification strategies on the Swedish real estate market, comparing: (1) cor- relation matrices, (2) efficient frontiers, (3) Sharpe ratios, (4) coefficients in equations explaining total returns and (5) $R^{2}$ values in equations explaining total returns. Four out of five methods clearly show that property type diversification is more efficient in terms of risk reduction than diversifying over regions on the Swedish real estate market. For the only test (4) that favours regions, the results are not significant. All results based on historic performance should be used with caution however and this is especially true for the housing market in Sweden where past return has had the uncommon feature of high return and low risk. The Swedish housing market is under regulation, and past return might not be a good indication of the future. There is uncertainty about the continued transformation to co-ops and the prevalence of rent control, which makes predictions about future housing return difficult.

It is apparent that correlations in return between property types and regions are not stable over time, since average correlations drop significantly when using a time series that starts after the 1990 crash on the Swedish property market. As a suggestion for future research, it would be interesting to formally test for co integration and structural breaks. This is not yet possible on the Swedish property market due to a lack of data, but can and should be done in the future. Another topic for future research would be to focus on classifications and identify economic regions in the Swedish property market. Risk reduction using geographic regions could then be compared to the regions used in this study.

\section{REFERENCES}

Brooks, C.; Tsolacos, S. 2010. Real estate modelling and forecasting. Cambridge University Press. http://dx.doi.org/10.1017/CBO9780511814235

Byrne, P.; Lee, S. 2011. Sector, region or function? A MAD reassessment of real estate diversification in Great Britain, Journal of Property Investment \& Finance 29(2): 167-189. http://dx.doi. org/10.1108/14635781111112783

Cheng, P.; Liang, Y. 2000. Optimal diversification: is it really worthwhile?, Journal of Real Estate Portfolio Management 6(1): 7-16.

Eichholtz, P. M.; Hoesli, M.; MacGregor, B. D.; Nanthakumaran, N. 1995. Real estate portfolio diversification by property type and region, Journal of Property Finance 6(3): 39-59. http://dx.doi. org/10.1108/09588689510101676

Elsinga, M.; Lind, H. 2013. The effect of EU-legislation on rental systems in Sweden and the Netherlands, 
Housing Studies 28(7): 960-970. http://dx.doi.org/10. 1080/02673037.2013.803044

Fisher, J. D.; Liang, Y. 2000. Is sector diversification more important than regional diversification?, Real Estate Finance 17(3): 35-40.

Gabrielli, L.; Lee, S. 2009. The relative importance of sector and regional factors in Italy, Journal of Property Investment \& Finance 27(3): 277-289. http://dx.doi.org/10.1108/14635780910951975

Gallo, J.; Lockwood, L.; Zhang, Y. 2013. Structuring global property portfolios: a cointegration approach, Journal of Real Estate Research 35(1): 53-81.

Geltner, D. 1993. Estimating market values from appraised values without assuming an efficient market, Journal of Real Estate Research 8(3): 325-345.

Gibbons, M. R.; Ross, S. A.; Shanken, J. 1989. A test of the efficiency of a given portfolio, Econometrica 57(5) 1121-1152. http://dx.doi.org/10.2307/1913625

Hartzell, D.; Hekman, J.; Miles, M. 1986. Diversification categories in investment real estate, Real Estate Economics 14(2): 230-254. http://dx.doi. org/10.1111/1540-6229.00385

Hartzell, D.; Shulman, D.; Wurtzebach, C. 1987. Refining the analysis of regional diversification for income-producing real estate, Journal of Real Estate Research 2(2): 85-95.

Heston, S. L.; Rouwenhorst, K. G. 1994. Does industrial structure explain the benefits of international diversification?, Journal of Financial Economics 36(1): 3-27. http://dx.doi.org/10.1016/0304-405X(94)90028-0

Heydenreich, F. 2010. Economic diversification: evidence for the United Kingdom, Journal of Real Estate Portfolio Management 16(1): 71-85. http://dx.doi. org/10.2139/ssrn. 1575525

Hoesli, M.; Lekander, J.; Witkiewicz, W. 2003. Real estate in the institutional portfolio: a comparison of suggested and actual weights, Journal of Alternative Investments 6(3): 53-59. http://dx.doi.org/10.3905/ jai.2003.319099

Jennrich, R. I. 1970. An asymptotic $\chi^{2}$ test for the equality of two correlation matrices, Journal of the American Statistical Association 65(330): 904-912. http://dx.doi.org/10.2307/2284596

Jobson, J. D.; Korkie, B. 1982. Potential performance and tests of portfolio efficiency, Journal of Financial Economics 10(4): 433-466. http://dx.doi. org/10.1016/0304-405X(82)90019-8

Jobson, J. D.; Korkie, B. M. 1981. Performance hypothesis testing with the Sharpe and Treynor measures, Journal of Finance 36(4): 889-908. http://dx.doi. org/10.1111/j.1540-6261.1981.tb04891.x
Lee, S. 2001. The relative importance of property type and regional factors in real estate returns, Journal of Real Estate Portfolio Management 7(2): 159-167.

Lee, S.; Byrne, P. 1998. Diversification by sector, region or function? A mean absolute deviation optimization, Journal of Property Valuation and Investment 16(1): 38-56. http://dx.doi.org/10.1108/14635789810205119

Malizia, E. E.; Simons, R. A. 1991. Comparing regional classifications for real estate portfolio diversification, Journal of Real Estate Research 6(1): 53-77.

Markowitz, H. 1952. Portfolio selection, Journal of Finance 7(1): 77-91. http://dx.doi.org/10.1111/j.1540-6261.1952. tb01525.x

Miles, M.; McCue, T. 1984. Commercial real estate returns, Real Estate Economics 12(3): 355-377. http://dx.doi.org/10.1111/1540-6229.00327

Mueller, G. 1993. Refining economic diversification strategies for real estate portfolios, Journal of Real Estate Research 8(1): 55-68.

Mueller, G.; Ziering, B. 1992. Real estate portfolio diversification using economic diversification, Journal of Real Estate Research 7(4): 375-386.

Nordlund, B. 2004. What kind of information from the market is employed as basis for appraisal of commercial real estate?, Dept. of Building and Real Estate Economics KTH.

Olaleye, A.; Aluko, B.; Oloyede, S. 2008. Evaluating diversification strategies for direct property investment portfolios, Journal of Real Estate Portfolio Management 14(3): 223-232.

Schuck, E. J.; Brown, G. R. 1997. Value weighting and real estate portfolio risk, Journal of Property Research 14(3): 169-187. http://dx.doi. org/10.1080/095999197368591

Seiler, M.; Webb, J.; Myer, N. 1999. Diversification issues in real estate investment, Journal of Real Estate Literature 7(2): 163-179. http://dx.doi. org/10.1023/A:1008741320860

Sharpe, W. F. 1964. Capital asset prices: a theory of market equilibrium under conditions of risk, Journal of Finance 19(3): 425-442. http://dx.doi. org/10.1111/j.1540-6261.1964.tb02865.x

Tarbert, H. 1998. The long-run diversification benefits available from investing across geographical regions and property type: evidence from cointegration tests, Economic Modelling 15(1): 49-65. http://dx.doi. org/10.1016/S0264-9993(97)00011-4

Viezer, T. 2000. Evaluating "within real estate" diversification strategies, Journal of Real Estate Portfolio Management 6(1): 75-95.

Ziering, B.; Hess, R. 1995. A further note on economic versus geographic diversification, Real Estate Finance 12: 53-60. 